\title{
Best pasture management practice adoption and sediment abatement
}

\author{
Dayton M. Lambert ${ }^{1, *} \mathbb{D}$, Christopher D. Clark ${ }^{2}$, Laura J. Medwid ${ }^{3}$, Shawn A. Hawkins ${ }^{4}$ \\ and Hannah A. McClellan ${ }^{4}$ \\ ${ }^{1}$ Department of Agricultural Economics, Oklahoma State University, Stillwater, Oklahoma, USA, ${ }^{2}$ Department of Agricultural \\ and Resource Economics, University of Tennessee, Knoxville, Tennessee, USA, ${ }^{3}$ Department of Agricultural, Food, and \\ Resource Economics, Michigan State University, East Lansing, Michigan, USA and ${ }^{4}$ Department of Biosystems \\ Engineering and Soil Science, University of Tennessee Institute of Agriculture, Knoxville, Tennessee, USA \\ ${ }^{\star}$ Corresponding author. Email: dayton.lambert@okstate.edu
}

\begin{abstract}
Research on producer willingness to adopt individual best pasture management practices (BMPs) is extensive, but less attention has been paid to producers simultaneously adopting multiple, complementary BMPs. Applications linking primary survey data on BMP adoption to water quality biophysical models are also limited. A choice-experiment survey of livestock producers is analyzed to determine willingness to adopt pasture BMPs. Sediment abatement curves are derived by linking estimates of producer responsiveness to incentives to adopt rotational grazing with a biophysical simulation model. Current cost share rates of $\$ 24 /$ acre should yield a $12 \%$ decrease in sediment loading from pastures.
\end{abstract}

Keywords: Censored system; choice experiment; convexity; rotational grazing; sediment; willingness to adopt

JEL Classifications: C3; Q12; Q2

\section{Introduction}

One approach for reducing soil loss caused by poorly managed pasture is to offer beef cattle producers incentives to adopt best pasture management practices (BMPs). Research on the voluntary adoption of BMPs is extensive (Baumgart-Getz, Prokopy, and Flores, 2012; Knowler and Bradshaw, 2007; Liu, Bruins, and Heberling, 2018; Pannell, Llewellyn, and Corbeels, 2014; Prokopy et al., 2008). A number of these studies focus on forage or pasture BMPs adopted by livestock producers (e.g., Gillespie, Kim, and Paudel, 2007; Jensen et al., 2015; Kim, Gillespie, and Paudel, 2005, 2008). Examples of these BMPs include rotational grazing, water tanks, stream crossings, and pasture rehabilitation. The private benefits of managing pasture with one or a combination of these practices include increased forage yield, reduction in soil erosion, and improved herd health. Off-site benefits from implementing these practices include reduced sediment loading into streams and waterways, improved water quality, and increased use and nonuse values. The private benefits to producers from adopting BMPs are offset by the costs of structure installation and maintenance. From the perspective of an agency mediating public demand for off-site water quality improvements, adoption incentives are expected to increase the provision of off-site benefits by tilting the calculus of private operators in favor of BMP adoption. Given adoption, the extent or intensity with which a producer implements a technology is also expected to be positively related to the incentives provided (Smale and Heisey, 1993).

(C) The Author(s) 2020. This is an Open Access article, distributed under the terms of the Creative Commons Attribution-NonCommercialShareAlike licence (http://creativecommons.org/licenses/by-nc-sa/4.0/), which permits non-commercial re-use, distribution, and reproduction in any medium, provided the same Creative Commons licence is included and the original work is properly cited. The written permission of Cambridge University Press must be obtained for commercial re-use. 
Information asymmetries between producers and implementing agencies and heterogeneity across producers and landscapes complicate the analysis of the effects incentives have on BMP adoption and the desired off-site environmental outcomes. Variations in producer willingness to adopt arise from differences in BMP suitability and effectiveness in promoting livestock production, while variations in BMP effectiveness in reducing environmental externalities can be traced to heterogeneity in landscape features and other farm and farmer characteristics. These differences manifest directly or indirectly through differences in the scope and scale at which a BMP is adopted, which can also lead to variation in performance effectiveness.

This research analyzes the results of a hypothetical choice experiment from a mail survey to elicit the willingness of beef cattle producers to adopt four pasture BMPs-rotational grazing, water tanks, stream crossings, and pasture rehabilitation-in the Oostanaula Creek watershed in East Tennessee (Hydrologic Unit Code TN06020002083; ${ }^{1}$ details of BMPs in online supplementary Appendix I). Each of these BMPs confers both on-site (private) benefits, such as increased forage productivity, and off-site (public) benefits, such as improved water quality. Pasture improvement requires reseeding or planting grasses to increase forage yield and repair overgrazed areas (bare spots) and erosion. Water tank systems provide cattle a source of water other than streams or ponds, thereby increasing pasture utilization and reducing nutrient and sediment loading to streams. Stream crossings protect stream banks from erosion. Rotational grazing enhances forage quality and productivity by resting pasture.

Adoption of a practice is a discrete event (adoption/nonadoption), whereas the intensity (or scale) of implementation is a continuous variable (e.g., acres allocated to rotational grazing) or count (e.g., water tanks). In this study, estimation of producer response to monetary incentives maintains economic conditions consistent with profit maximizing behavior. To the authors' knowledge, this study is the first to use a choice experiment to estimate pasture BMP adoption as a theoretically consistent system of supply equations that integrates to an indirect profit function. Best management practice supply functions are modeled as a censored system using a two-step estimation procedure while imposing convexity. An empirical application links the supply function estimates with a biophysical simulation model to determine the effect of changing incentive levels on sediment reduction. We adopt the optimization approach suggested by Govindasamy and Huffman (1993), Govindasamy and Cochran (1995), and Smith et al. (2014). Smith et al. find that targeted BMP programs are more cost effective than those "randomly" implemented with an incentive equally mandated throughout a watershed. The optimization approach we apply here builds on their premise but parameterizes sedimentation reduction with econometric estimates of producer willingness to adopt and implement pasture BMPs. Applications of this method could encourage agencies to consider ex ante the effects of both own- and cross-incentive elasticities on BMP adoption and sediment abatement when setting incentives for complementary BMPs.

\section{Conceptual model}

The pasture BMPs analyzed are designed to increase forage productivity and reduce sedimentation. Components of forage management considered here include rotational grazing $(R)$ and pasture improvement $(P)$. Producers can augment forage productivity by rotating cattle on pasture and reestablishing grasses and legumes on bare soils. Cattle have access to water tanks $(W)$ in enclosed paddocks. Producers may also connect paddocks on opposite sides of a stream with fenced crossings (stream crossings, $S$ ) to stabilize stream banks and ensure animal safety.

The changes in net revenue $(\Delta \pi)$ livestock producers might expect from accepting an incentive to adopt a BMP are approximated with a symmetric normalized quadratic indirect profit function (SNQ) (Diewert and Wales, 1987; Kohli, 1993). The SNQ approximation is a linearly

\footnotetext{
${ }^{1} \mathrm{~A}$ map of the watershed is given by Lambert et al. (2014).
} 
homogeneous, flexible functional form that allows the signs of cross-price elasticities to be unrestricted (Diewert and Wales, 1987). The advantage of the SNQ system, rather than the "standard" normalized quadratic profit function (Chambers, 1988), is that one need not arbitrarily designate a netput as a numeraire. As Paudel and McIntosh (2007) indicated, the signs and magnitudes of elasticties calculated from the standard form of the normalized quadratic profit function may vary, depending on the numeraire choice.

Returns from adopting a practice are approximated as a second-order expansion around an arbitrary normalized indirect profit function with incentives $(v)$ the decision variable,

$$
\Delta \pi_{i}=\sum_{\ell=1}^{L} b_{\ell} \cdot v_{i \ell}+\frac{1}{2} c_{i}^{-1} \sum_{\ell=1}^{L} \sum_{m=1}^{L} b_{\ell m} \cdot v_{i \ell} \cdot v_{i m}+o\left(u_{i}\right)
$$

where $\ell=P, R, W, S$; index $m$ aliases $\ell ; i$ indexes producers; $\mathrm{o}\left(u_{i}\right)$ is a truncation remainder of the expansion with an expected mean of zero and constant variance; $\left(b_{\ell}, b_{\ell m}\right)$ are linear and quadratic slope parameters, respectively, with $b_{\ell m}=b_{m \ell}, \ell \neq m$ (symmetry restriction); and $c_{i}=\sum_{\ell=1}^{L} \omega_{i \ell} \cdot v_{i \ell}$, a normalizing index with $\omega_{i \ell}$ a predetermined weight. We use the normalization strategy suggested by Diewert and Wales (1992) such that the predetermined weights sum to 1 and vary across producers. In the absence of monetary incentives encouraging BMP adoption, $\Delta \pi=0$.

Differentiating the profit function with respect to incentives results in a linear system of equations, with the typical BMP supply function,

$$
q_{i \ell}=b_{\ell}+c_{i}^{-1} \sum_{\ell=1}^{L} b_{\ell m} \cdot v_{i \ell}-\frac{\omega_{i \ell}}{2 \cdot c_{i}^{2}} \sum_{\ell=1}^{L} \sum_{m=1}^{L} b_{\ell m} \cdot v_{i \ell} \cdot v_{i m}+u_{i}^{\ell}
$$

where $q_{i \ell}$ are the BMP acres or number of structures adopted, given the offered incentive, and the $\boldsymbol{u}$ 's are independent and identically distributed errors with covariance $\boldsymbol{\Sigma}$. The supply system of equation (2) is differentiated with respect to own- and cross-incentives to calculate elasticities. Own- and cross-incentives characterize producer responsiveness to incentives in terms of the percentage change in the quantity of the BMP supplied for each $1 \%$ change in the incentive.

\subsection{Censored system and convexity}

The extent of BMP adoption is censored at zero when a producer refuses an offered incentive. This problem complicates estimation of typical producer or consumer demand systems because of crossequation residual correlation caused by the symmetry restrictions. The applied econometrics literature has generally approached quantity-censoring problems from the consumer side, but the logic supporting the estimation procedures extends directly to estimation of indirect profit functions. Shonkwiler and Yen (1999) introduced an inefficient but consistent procedure to estimate constrained censored demand systems. Su and Yen (2000) and Yen, Kan, and Su (2002) applied the two-step approach to estimate demand for meat and fats and oils, respectively. Other two-step approaches include Perali and Chavas's (2000) minimum distance estimator. More efficient maximum likelihood (ML) estimators for censored demand systems were developed by Yen (2005) and applied by Yen and Lin (2006). Bayesian Markov chain Monte Carlo estimators have also been used to estimate demand systems with censoring (Kasteridis, Yen, and Feng, 2011).

This analysis extends the two-step censored system estimator of Yen, Kan, and Su (2002) to model the voluntary adoption of BMPs by producers given cost share incentives. From equation (2), set $\boldsymbol{\beta}=\left(b_{P}, b_{R}, b_{W}, b_{S}, b_{P P}, b_{R R}, b_{W W}, b_{S S}, b_{P R}, b_{P W}, b_{P S}, b_{R W}, b_{R S}, b_{W S}\right)^{\prime}$. Then, for the $\ell$ th pasture BMP conditioned on the producer's willingness to adopt the BMP given the offered incentive, the quantity of the BMP supplied by the producer is

$$
q_{i \ell}=\left\{\begin{array}{cc}
\mathbf{x}_{i(\ell)} \boldsymbol{\beta}_{(\ell)}+u_{i}^{\ell} & \text { if } \\
0 & \mathbf{z}_{i} \boldsymbol{\gamma}_{\ell}+\epsilon_{i}^{\ell}>0 \\
\text { otherwise }
\end{array}\right.
$$


where $\mathbf{z}_{i}$ are variables hypothesized to influence the producer's decision to adopt BMP $\ell$ apart from the offered incentives; $\boldsymbol{\gamma}_{\ell}$ are parameters; $\epsilon_{i}^{\ell}$ is a random error term, and the product $\mathbf{z}_{i} \boldsymbol{\gamma}_{\ell}$ is a linear index function (Maddala, 1983). The stochastic terms of the adoption and supply equations share common omitted factors because of the cross-equation parameter restrictions (e.g., adopt $=1$ when $\epsilon_{i}^{\ell}>-\mathbf{z}_{i} \boldsymbol{\gamma}_{\ell}$ ) and acres allocated to (or units of) a BMP. This feature could cause correlation between the residuals of the index functions and their respective quantity equations. The selection mechanism is typically modeled as a standard normal random variable with the probability of adoption $\Phi\left(\mathbf{z}_{i} \boldsymbol{\gamma}_{\ell}\right)$ (the standard normal cumulative density function, CDF), and a corresponding standard normal probability density $\phi\left(\mathbf{z}_{i} \boldsymbol{\gamma}_{\ell}\right)$ (the standard normal probability density function, PDF). The parameters are estimated with probit regression and ML. It is important to note that the incentives do not appear in the index function because of the homogeneity and symmetry constraints required by the indirect profit function (e.g., Yen and Lin, 2006). Thus, the linear index function only includes nonpecuniary variables corresponding with operator attributes and farm structure and management characteristics. The unconditional mean of the BMP quantity supplied by a producer is

$$
E\left(q_{i \ell} \mid \mathbf{x}_{i(\ell)}, \mathbf{z}_{i \ell}\right)=\Phi\left(\mathbf{z}_{i \ell} \boldsymbol{\gamma}_{\ell}\right) \cdot \mathbf{x}_{i(\ell)} \boldsymbol{\beta}_{(\ell)}+\lambda_{\ell} \cdot \phi\left(\mathbf{z}_{i \ell} \boldsymbol{\gamma}_{\ell}\right),
$$

where $\lambda_{\ell}$ is the covariance between the error terms of the participation decision and the quantity of the BMP adopted; that is, $\lambda_{\ell}=\rho_{\ell} \cdot \sigma_{\ell}$ (Cameron and Trivedi, 2005; Maddala, 1983; Shonkwiler and Yen, 1999).

An advantage of the SNQ indirect profit function is that global convexity can be imposed using ex post procedures (Henningsen and Henning, 2009; Koebel, 1998; Perali and Chavas, 2000) or by directly estimating the Cholesky factorization of the Hessian matrix (e.g., Diewert and Wales, 1987; Lau, 1978). Any positive semidefinite matrix can be written as $\mathbf{B}=\mathbf{A} \mathbf{A}^{\prime}$, where $\mathbf{A}$ is a lower-triangular matrix. Then, for the parameters in $\mathbf{B}$,

$$
\mathbf{A}=\left[\begin{array}{cccc}
a_{P P} & 0 & 0 & 0 \\
a_{R P} & a_{R R} & 0 & 0 \\
a_{W P} & a_{W R} & a_{W W} & 0 \\
a_{S P} & a_{S R} & a_{S W} & 0
\end{array}\right],
$$

where $a_{S S}=0$ such that $\mathbf{A}^{\prime} \mathbf{1}=\mathbf{0}$ (Diewert and Wales, 1992). This restriction ensures the homogeneity requirement $b_{\ell \ell}=-\sum_{\ell=1, m \neq \ell}^{L} b_{\ell m}$. The $\left[\alpha_{\ell m}\right]$ elements enter directly into the system defined in equation (2) and are estimated with ML, along with the PDF and CDF evaluated at the first-stage probit ML estimates.

\subsection{Estimation}

The system is estimated with iterated feasible generalized nonlinear least squares (IFGNLS), which converges to the ML estimator (Zellner, 1962), using the ifgnls option in STATA's nlsur routine (StataCorp, 2015). Applying IFGNLS in the second step yields consistent estimators because the ML probit estimates of $\boldsymbol{\gamma}$ are consistent (Shonkwiler and Yen, 1999).

Breusch and Pagan's (1980) test is used to determine if the seemingly unrelated regression (SUR) error covariance matrix is diagonal. The null hypothesis is $H_{0}: \sigma_{P R}=\sigma_{P W}=$ $\sigma_{P S}=\sigma_{R W}=\sigma_{R S}=\sigma_{W S}=0$. Under this null, the test statistic is a chi-square random variable with six degrees of freedom and a critical value of 12.59 at the $5 \%$ level of significance. A likelihood ratio (LR) test is used to select the preferred model, with the null hypothesis $H_{0}: \lambda_{P}=\lambda_{R}=\lambda_{W}=\lambda_{S}=0$. The test is a chi-squared random variable with four degrees of freedom and a critical value of 9.49 at the $5 \%$ level of significance.

Yen, Kan, and Su (2002) suggest estimating the error covariance of the two-step censored system using a Murphy-Topel estimator. This application uses a jackknife covariance procedure to estimate the parameter covariance matrix (Perali and Chavas, 2000). The probit regression, the 
standard normal CDF and PDF, and the system of BMP supply equations were reestimated with IFGNLS for each jackknife replicate. Standard errors of the regression coefficients are estimated as the mean squared error difference between the replicate parameters and the parameters estimated with the original data set. Own- and cross-incentive elasticities are calculated for each jackknife replicate, with the lower $5 \%$ and upper $95 \%$ bounds determined by the elasticity distributions.

\subsection{Application: adoption of survey best pasture management practices}

Sediment load reductions generated by rotational grazing and the suite of the survey BMPs, including improved pasture management, water tanks, and stream crossings, are simulated by maintaining minimum pasture forage stands. The ArcSWAT (Version 2012, Release 10) graphical user interface was used to develop a Soil and Water Assessment Tool (SWAT) model of the Oostanaula Creek watershed in ArcGIS Desktop (ESRI, Version 10.5). SWAT is a physically based model developed to simulate land-management and rainfall-runoff processes in predominantly agricultural watersheds with a high level of spatial detail using hydrologic response units (HRUs). HRUs are unique combinations of soil type, slope, and land use/management practices (Gassman et al., 2007).

For the adoption effects analysis, management practice modifications were made to pasture HRUs. Land use, soils, and digital elevation data were downloaded from the U.S. Department of Agriculture's (USDA) Geospatial Data Gateway (USDA, Natural Resource Conservation Service [NRCS], 2018). Land use corresponded with the 2009 Croplands Data Layer (Johnson and Mueller, 2010). Soil types were classified according to the State Soil Geographic (STATSGO) data set (Wang and Melesse, 2006). Slopes (0-2\%, 2\%-8\%, 8\%-16\%, and >16\%) were established using the National Elevation Dataset (10 m resolution; Gesch et al., 2002). Rainfall input data for the model were obtained from the National Weather Station Coop database for two stations in Athens and Cleveland, Tennessee (Leeper, Rennie, and Palecki, 2015). Models were run from January 1990 to October 2013, with a monthly time step and a two-year startup period. Model development, calibration, and validation details are provided in online supplementary Appendix II.

A total of 466 HRUs represented the watershed's unique land use/slope/soil combinations. Of these, 207 were classified as pasture, representing a total of 18,114 acres. Fescue forage was produced in pasture HRUs using fertilization and grazing management routines (online supplementary Appendix II). The adoption of the survey suite of BMPs was modeled through modifications to the management practice schedule for grazed fescue ("FESC") land use category by varying the BIOMIN setting. This BIOMIN setting is used in SWAT to avoid pasture damage and increased erosion caused by overgrazing (White et al., 2010). This procedure constrains minimum vegetation in kilograms of dry matter per hectare after which grazing is discontinued. A calibrated and validated model run with a BIOMIN setting of 300 was completed to assess sediment loss when the potential for severely overgrazed pastures existed. A second model run with a BIOMIN setting of 1,000 was used to assess sediment loss potential after implementing the suite of survey BMPs.

Fifty-two of the 207 pasture HRUs accounted for $90 \%$ of the annual sediment runoff from pasture (Figure 1). ${ }^{2}$ The total area represented by these 52 HRUs was 4,821 acres. In the absence of rotational grazing on any of these pasture HRUs (BIOMIN setting of 300), the SWAT model estimated an annual sediment yield of 22,839 tons/year from the watershed's pastureland. When rotational grazing was implemented on the 52 pasture HRUs (BIOMIN setting of 1,000), the annual sediment yield from these HRUs decreased to 13,230 tons/year. Thus, the ability to identify and differentiate land use/soil/slope combinations offers the potential for more cost-effective sediment abatement.

\footnotetext{
2"Pasture" is based on the NRCS classification.
} 


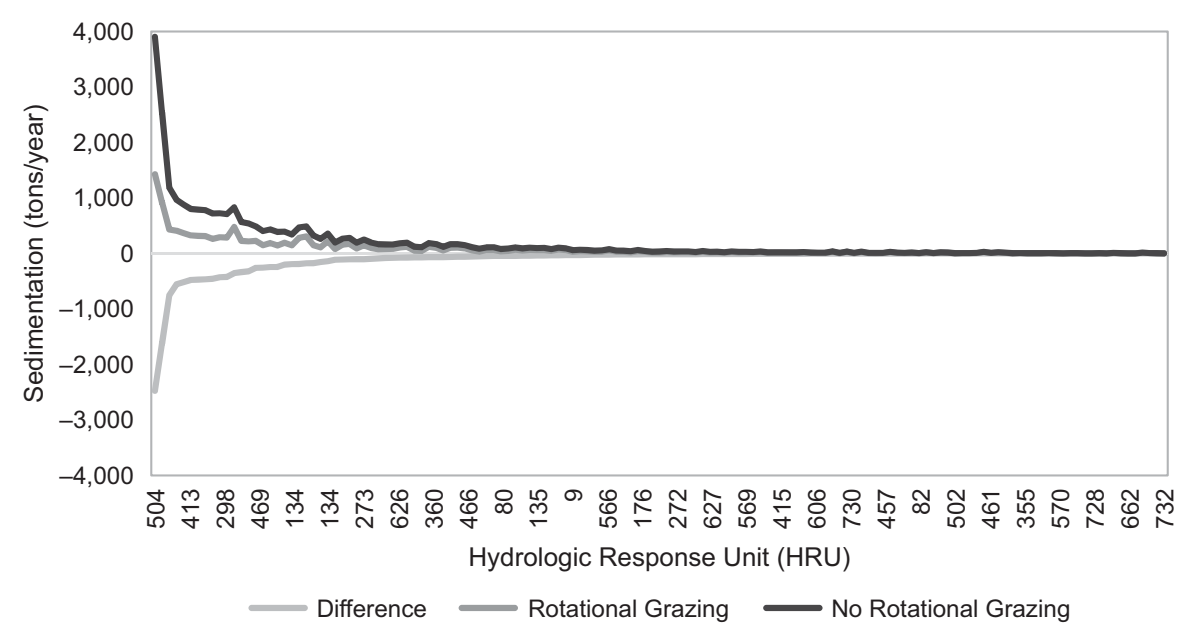

Figure 1. Distribution of differences in sedimentation loading for hydrologic response units managed with and without rotational grazing.

The simulation focuses on the adoption of the survey suite of BMPs to increase forage productivity and reduce sediment runoff from pasture. The total program cost of achieving a sediment abatement goal for the watershed could be calculated as the solution to a cost minimization problem, subject to producer responsiveness to monetary incentives encouraging the enrollment of pasture acres into the hypothetical rotational grazing program. Along these lines, we adopt the optimization approach suggested by Govindasamy and Huffman (1993) and Smith et al. (2014). Parameters and variables used to estimate the cost of meeting a sediment abatement target through the adoption of rotational grazing are in Table 1.

The optimization problem minimizes the cost of reaching a watershed sediment abatement goal by choosing an HRU-specific incentive to encourage enrollment of pasture acres into the hypothetical program, subject to producer willingness to enroll acres into the program and animal water requirements. ${ }^{3}$ By allowing incentives to vary among HRUs, we are implicitly assuming that the agency administering the incentive program has the information and authority to discriminate among land uses based on sediment loading rates.

The objective function for the optimization problem is

$$
\min _{p_{R(k)}>0} \sum_{k=1}^{52} p_{R(k)} \cdot q_{R(k)}
$$

subject to:

$$
\begin{gathered}
S_{k}=S_{0(k)}+S_{1(k)} \forall k . \\
\sum_{k=1}^{52} S_{k}=Q . \\
q_{R(k)}=\hat{b}_{R R} \cdot\left(\frac{p_{R(k)}}{\bar{c}}\right)\left[1-\frac{\bar{\omega} R}{2} \cdot\left(\frac{p_{R(k)}}{\bar{c}}\right)\right] \forall k . \\
q_{R(k)} \leq T_{k} \forall k .
\end{gathered}
$$

The objective minimizes the total cost of enrolling private pasture into the rotational grazing program, with $p_{R(k)}$ the dollars per acre paid annually to producers in HRU $k$ (equation 6). Equation

\footnotetext{
${ }^{3}$ The NRCS does not vary incentives based on an HRU. However, NRCS can choose or not choose a county or increase or decrease conservation budgets based on the severity of problems.
} 
(7) is the total amount of sediment loading generated by the $k$ th HRU from areas managed with and without rotational grazing. The sediment abatement target is equation (8), which aggregates sediment (annual tons) loading across the watershed. Equation (9) is the estimated acreage supply equation for rotational grazing from the normalized quadratic profit function. The parameter $\bar{c}$ is the average of Diewert and Wales's (1992) price index over the sample $(\bar{c}=351)$, and $\bar{\omega}_{R}$ the sample average of the weighting factors for rotational grazing $\left(\bar{\omega}_{R}=0.08\right)$. The intercept term is omitted because, in the absence of incentives, enrollment of pasture acres into the hypothetical rotational grazing program would be zero. The number of acres enrolled into the program cannot exceed the total available acres in HRU $k\left(T_{k}\right.$, equation 10$)$.

The rotational grazing acreage supply equation is used to generate a watershed abatement curve. The abatement curve represents the dollars per ton the agency would have to pay in incentives to achieve an annual sediment target. Enrollment of pasture acres into rotational grazing is calculated for each HRU at the optimized incentives, corresponding with a target level of sediment. Then, using equation (7), the change in sediment loading because of the pasture managed under a rotational grazing system of BMPs $\left(q_{R(k)} \cdot\left[r_{0(k)}-r_{1(k)}\right]\right)$ is aggregated across HRUs at a given per acre incentive offered to producers to manage pasture acres using rotational grazing. The dollar per acre incentive is converted to dollar per sediment ton using the sediment yield parameters $\left(r_{0(k)}\right.$ and $r_{1(k)}$, Table 1$)$ generated by SWAT. We vary the target sedimentation level $Q$ from 13,000 to 22,800 tons/year in increments of 426 tons (24 intervals), solving the problem at each target with the General Algebraic Modeling System (GAMS Development Corporation) using a sparse nonlinear optimization procedure (snopt).

Project costs used to calculate the abatement curves include the incentives paid for the installation of water tanks. Water tanks are required when animals are in paddocks for rotational grazing and prevented from accessing streams or ponds. The number of water tanks required was calculated based on cattle water requirements and the number of beef cattle that could be supported by the optimal enrolled acreage levels for the different sediment targets. The number of beef cattle (BeefCattle) that can be supported by pasture forage in HRU $k$ is (Undersander et al., 2002)

$$
\text { BeefCattle }_{k}=\frac{q_{R(k)} \times \text { Forage Yield }}{\text { Forage Access } \times \text { Animal Weight } \times \text { Days Grazed }} .
$$

Forage productivity (Forage Yield) is assumed to be 4,000 lb./acre (Undersander et al., 2002), and animal forage requirements (Forage Access) assumes that animals require $4 \%$ of their live weight in forage per grazing day (Undersander et al., 2002). Based on what is typical for the region's pasture forage systems, we also assume a 153-day grazing period (Days Grazed) and a finishing weight of 1,250 lb. (Animal Weight).

The number of water tanks required in a rotational grazing paddock in an HRU $\left(q_{W T(k)}\right)$ was determined as the number of beef cattle supported by the HRU times the gallons per day consumed by each animal (10 gallons/animal/day; Undersander et al., 2002) divided by the tank size (800 gallons):

$$
q_{W(k)}=\frac{10 \times \text { BeefCattle }_{k}}{800} .
$$

The $75 \%$ cost share rate of $\$ 1,150$ per 800 -gallon tank was held constant across the water shed.

\section{Data}

The survey of beef cattle producers was conducted in 2011 and 2013. Respondents were mailed an initial package that included an introductory letter, a booklet questionnaire, and a return stamped envelope. A reminder postcard was mailed 1 week later, and, for nonresponders, a second packet (cover letter, questionnaire, and return envelope) was sent 2 weeks later. The sample was collected 
Table 1. Parameters and variables used in the optimization procedure

\begin{tabular}{|c|c|c|}
\hline Parameters and Variables & Definition & Units \\
\hline$T_{k}$ (parameter) & Total pasture area in HRU $k$ & acres \\
\hline$q_{R(k)}$ (variable) & HRU k's area in rotational grazing & acres \\
\hline$q_{W(k)}$ (parameter) & Water tanks ( 800 gallons), HRU $k$ & count \\
\hline$r_{0(k)}$ (parameter) & HRU k's sediment loading rate, no rotational grazing & tons/acre/year \\
\hline$r_{R G(k)}$ (parameter) & HRU k's sediment loading rate, rotational grazing & tons/acre/year \\
\hline$p_{R(k)}$ (variable) & Per acre incentive for rotational grazing & $\$$ /acre \\
\hline $\bar{p}_{W}$ (parameter) & Unit cost for water tank & $\$ 1,150$ \\
\hline$S_{0(k)}=r_{0(k)} \cdot\left(T_{k}-q_{R(k)}\right)$ & Sediment load for HRU $k$ not in rotational grazing & tons/year \\
\hline$S_{1(k)}=r_{R G(k)} \cdot q_{R(k)}$ & Sediment load for HRU $k$ in rotational grazing & tons/year \\
\hline$S_{k}=S_{0(k)}+S_{1(k)}$ & Total sediment load in HRU $k$ & tons/year \\
\hline$Q=\sum_{k} S_{k}$ & Target sediment load in watershed & tons/year \\
\hline Forage Yield & Forage yield for pasture & $4,000 \mathrm{lb} . / \mathrm{acre}$ \\
\hline Animal Weight & Target animal weight & $1,250 \mathrm{lb}$ \\
\hline Days Grazed & Days animals grazed on forage & 153 days \\
\hline Feed Access & Feed requirement & $0.04 \%$ \\
\hline
\end{tabular}

Notes: $\mathrm{HRU}$, hydrologic response unit (see text for definitions); $P$, pasture improvement; $R$, rotational grazing; $S$, stream crossing; $W$, water tank.

using addresses from a publicly available tax parcel list frame, which included the physical addresses, boundaries, assessed property values, and land use classifications of the parcels. Survey responses of livestock producers were collected in two waves for budgetary and logistical reasons. The first mailing was sent in March 2011 to 1,480 owners of 1,736 unique parcels classified as agricultural land. The second wave was sent in February 2013 to 3,678 unique owners of 4,720 agricultural parcels. The response rate was $32 \%$. After removing observations with missing records and focusing only on beef cattle operations indicating access to a stream, there were 195 observations available for this analysis.

There were four sections in the survey. The questions in the first section, "Your Farm Operation," focused on producer and farm operation characteristics and the value respondents placed on objectives related to BMPs (e.g., improving forage quality and providing cattle access to a year-round supply of clean drinking water). The second section, "Best Management Practices," asked respondents about their previous experience with the BMPs (rotational grazing, water tanks, stream crossings, and pasture improvement) and included a hypothetical choice experiment to elicit producer willingness to adopt the BMPs. A description of the on- and offsite benefits and required actions for each BMP were provided to respondents on an informational page (online supplementary Appendix III).

Respondents were also provided per unit establishment and/or installation cost estimates for each BMP. These cost estimates-rotational grazing $=\$ 79.08 /$ ha $(\$ 32.00 /$ ac. $)$, pasture improvement $=\$ 626 /$ ha $(\$ 253.33 / \mathrm{ac}$.$) , stream crossing =\$ 41.63 / \mathrm{m}^{2}\left(\$ 3.87 / \mathrm{ft}^{2}{ }^{2}\right)$, and cattle water tanks $=\$ 1,533.33 /$ tank - were determined by dividing the equipment and practice cost share dollar amounts reported by the NRCS for Tennessee by the cost share rate used by the NRCS for Tennessee (0.75).

For the choice experiment, there were $4^{7}$ possible combinations of cost share amounts offered for the BMPs. The \%mktex macro (SAS version 9.2) was used to determine an optimal factorial design and the optimal number (49) of practice/incentive combinations (Lambert et al., 2014). 
Table 2. Summary statistics for practices, cost shares, and probit regressions

\begin{tabular}{|c|c|c|c|c|c|}
\hline & $\mathrm{N}$ & Mean & Standard Deviation & Minimum & Maximum \\
\hline \multicolumn{6}{|l|}{ Practices: } \\
\hline Pasture improvement (acres) & 146 & 60 & 63 & 5 & 400 \\
\hline Rotational grazing (acres) & 104 & 73 & 81 & 5 & 400 \\
\hline Water tanks (number) & 109 & 2.61 & 1.45 & 1 & 5 \\
\hline Stream crossing (square feet) & 47 & 921 & 1,095 & 100 & 5,000 \\
\hline \multicolumn{6}{|l|}{ Cost shares: } \\
\hline Pasture improvement (\$/acre) & 195 & 217 & 66 & 127 & 317 \\
\hline Rational grazing ( $\$$ /acre) & 195 & 28 & 8 & 16 & 40 \\
\hline Water tanks (\$/unit) & 195 & 1,362 & 367 & 767 & 1,917 \\
\hline Stream crossing ( $\$ /$ square foot) & 195 & 3.29 & 0.96 & 1.94 & 4.84 \\
\hline \multicolumn{6}{|l|}{ Probit model covariates: } \\
\hline Age (years) & 195 & 62.49 & 11.92 & 33 & 91 \\
\hline College $($ yes $=1)$ & 195 & 0.41 & & 0 & 1 \\
\hline Acres owned & 195 & 225.79 & 232.82 & 5 & 1,500 \\
\hline Percent area in pasture & 195 & 75.86 & 27.18 & 5 & 100 \\
\hline Pass on farm (yes $=1$ ) & 195 & 0.91 & & 0 & 1 \\
\hline Stocking density (beef cattle/area) & 195 & 0.78 & 1.10 & 0.05 & 12 \\
\hline Owned/operated area & 195 & 1.28 & 1.47 & 0.04 & 12 \\
\hline Use pasture improvement (yes $=1$ ) & 195 & 0.65 & & 0 & 1 \\
\hline Use stream crossing (yes $=1$ ) & 195 & 0.42 & & 0 & 1 \\
\hline Use rotational grazing (yes $=1$ ) & 195 & 0.61 & & 0 & 1 \\
\hline Use water tanks (yes $=1$ ) & 195 & 0.50 & & 0 & 1 \\
\hline Land value (\$/acre) & 195 & 4,932 & 1,647 & 518 & 8,408 \\
\hline Slope classification (scale, 1 to 4 ) & 195 & 2.70 & 0.88 & 1 & 4 \\
\hline
\end{tabular}

There were 49 versions of the survey mailed to respondents. The cost share amounts offered to producers were determined by multiplying the expected costs of the BMPs by $50 \%, 62.5 \%, 75 \%$, $87.5 \%, 100 \%, 112.5 \%$, and $125 \%$ (Table 2). Online supplementary Appendix III summarizes the distribution of cost share amounts and corresponding survey response frequencies. The survey presented respondents only with the dollar/unit amounts they would be eligible to receive for adopting a BMP. Respondents were not made aware that the dollar/unit amount corresponded with a specific cost share. The hypothetical cost share amounts varied randomly both between practices and across respondents.

Best management practice quantities that respondents were willing to adopt were scaled using a Laspeyres index benchmarked to the sum-product of the average quantity-incentive vectors of each practice. For each respondent, the index was calculated as $I_{i}=$ $\left(\sum v_{\ell} \cdot \bar{q}_{i \ell}\right) /\left(\sum \bar{v}_{\ell} \cdot \bar{q}_{i \ell}\right)$, where $v_{i \ell}$ is the incentive offered for practice $\ell$ to respondent $i$; and $\bar{q}_{\ell}$ and $\bar{v}_{\ell}$ are the sample averages of the quantity adopted of, and the incentive offered for, the $\ell$ th BMP, respectively. The indexed quantities used in the regressions are $\widetilde{q}_{i \ell}=q_{i \ell} / I_{i}$. This procedure rescales the BMP quantities to a common scale (Henningsen, 2018). Indexing 
the practices to a common scale is important in this analysis because the BMP quantity units are different for each practice.

\subsection{Operator and farm characteristics}

Operator and farm characteristics are hypothesized to influence the probability of adopting one or more of the BMPs (Table 2). Operator characteristics included in the probit adoption equations are age, educational attainment, and plans to pass on the farm to a family member. Farmers with more years of education may be inclined to adopt new technologies or practices (Daberkow and McBride, 2003; Roberts et al., 2004). Younger producers may be willing to experiment with new technologies because their planning horizons are longer (Schimmelpfennig and Ebel, 2011; Watcharaanantapong et al., 2014). A respondent's ties to the farm and the prospect of passing on the operation to kin could also effectively extend a respondent's time horizon and increase the likelihood of adopting BMPs (Claytor et al., 2018). Farmers who own relatively more of the land they operate may be more likely to adopt practices they perceive would improve the aesthetic or property value of their farm (Roberts et al., 2004). Higher property values may be associated with proximity to other parcels that have been developed for residential or commercial uses. The assessed per acre property value of the parcel may therefore also influence the decision to adopt a pasture BMP. Farm topography may also affect the decision to adopt pasture BMPs. Slope was assigned to parcels based on the majority of the area associated with the parcel classified into one of four categories represented in the watershed: $0-2 \%, 2 \%-8 \%, 8 \%-16 \%$, and $>16 \%$ slope (Medwid, 2016).

Farm operation variables include farm size, the percent of land farmed in pasture, and animal stocking density. Larger operations are more likely to adopt new technologies because of scale economies (Fernandez-Cornejo, Daberkow, and McBride, 2001). Farms allocating relatively more of the land they manage to pasture may be more likely to incorporate pasture BMPs into their operation (Jensen et al., 2015). Operations stocking pasture with cattle at relatively higher densities may also be more inclined to perceive the adoption of a suite of pasture BMPs as a way to sustain or increase productivity (Jensen et al., 2015). Familiarity and experience with each of the BMPs considered in this analysis may also explain willingness to participate in the hypothetical BMP incentive program.

\section{Results}

Seventy-five percent (146/195) of the respondents indicated willingness to adopt pasture improvement, given the incentive offered (Table 2). On average, respondents willing to improve their pasture were willing to rehabilitate 60 acres. Fifty-three percent $(104 / 195)$ of the respondents were willing to adopt rotational grazing, while 56\% (109/195) were willing to adopt water tanks. Respondents willing to adopt rotational grazing would enroll an average of 73 acres into the hypothetical program. Respondents willing to adopt water tanks would, on average, install 2.6 tanks. Twenty-four percent (46/195) of the respondents were willing to adopt stream crossings. Anecdotal evidence from extension agents working with cattle operators in the study's region reports that stream crossings are not popular with producers because of the effort needed to keep fences free of debris.

\subsection{Adoption of best pasture management practices}

The overall fit of the probit models ranges from 0.17 for stream crossings (McKelvey and Zavoina's [1975] $R^{2}$ ) to 0.36 for water tanks (Table 3). Correct predictions range from $62 \%$ for rotational grazing to $80 \%$ for pasture improvement. For all probit models, the joint null 
Table 3. Probit average marginal effects

\begin{tabular}{|c|c|c|c|c|}
\hline Variable & Pasture Improvement & Rotational Grazing & Water Tanks & Stream Crossing \\
\hline \multirow[t]{2}{*}{ Age (years) } & -0.003 & $-0.0055^{\star \star}$ & $-0.014^{\star * *}$ & $-0.0047^{\star}$ \\
\hline & $(0.0023)$ & $(0.0028)$ & $(0.0025)$ & $(0.0025)$ \\
\hline \multirow[t]{2}{*}{ College $($ yes $=1$ ) } & $0.1019^{\star}$ & 0.0896 & 0.0103 & 0.1061 \\
\hline & $(0.0603)$ & $(0.0706)$ & $(0.0687)$ & $(0.0639)$ \\
\hline \multirow[t]{2}{*}{ Acres owned } & $-0.0003^{\star \star \star}$ & $-0.0003^{\star}$ & 0.00003 & $0.0003^{\star \star \star}$ \\
\hline & $(0.0001)$ & $(0.0002)$ & $(0.0005)$ & $(0.0001)$ \\
\hline \multirow[t]{2}{*}{ Percent area in pasture } & -0.0008 & $-0.0034^{\star \star \star}$ & -0.0015 & 0.0008 \\
\hline & $(0.0013)$ & $(0.0014)$ & $(0.0013)$ & $(0.0013)$ \\
\hline \multirow[t]{2}{*}{ Pass on farm (yes $=1$ ) } & $0.2921^{\star \star \star}$ & $0.2152^{\star}$ & $0.2400^{\star \star}$ & 0.0072 \\
\hline & $(0.0832)$ & $(0.1127)$ & $(0.0930)$ & $(0.1029)$ \\
\hline \multirow[t]{2}{*}{ Stocking density (beef cattle/area) } & 0.0746 & $-0.0653^{\star *}$ & -0.0121 & 0.0151 \\
\hline & $(0.0602)$ & $(0.0312)$ & $(0.0390)$ & $(0.0265)$ \\
\hline \multirow[t]{2}{*}{ Owned/operated land } & -0.0145 & $0.0412^{*}$ & $-0.0421^{\star \star}$ & $-0.0375^{\star}$ \\
\hline & $(0.0175)$ & $(0.0238)$ & $(0.0196)$ & $(0.0225)$ \\
\hline \multirow[t]{2}{*}{ Use pasture improvement (yes $=1$ ) } & 0.0994 & $0.1495^{\star \star}$ & $0.1695^{\star \star \star}$ & -0.0249 \\
\hline & $(0.0645)$ & $(0.0715)$ & $(0.0681)$ & $(0.0711)$ \\
\hline \multirow[t]{2}{*}{ Use stream crossing (yes $=1$ ) } & -0.018 & -0.0019 & -0.0333 & 0.1035 \\
\hline & $(0.0581)$ & $(0.0633)$ & $(0.0666)$ & $(0.0627)$ \\
\hline \multirow[t]{2}{*}{ Use rotational grazing (yes $=1$ ) } & -0.0484 & $0.1453^{\star \star}$ & 0.0457 & 0.0366 \\
\hline & $(0.0613)$ & $(0.0719)$ & $(0.0692)$ & $(0.0642)$ \\
\hline \multirow[t]{2}{*}{ Use water tanks (yes $=1$ ) } & -0.0653 & -0.0658 & $0.1161^{\star}$ & $-0.1354^{\star \star \star}$ \\
\hline & $(0.0610)$ & $(0.0731)$ & $(0.0663)$ & $(0.0639)$ \\
\hline \multirow[t]{2}{*}{ Land value (\$/acre) } & -0.0268 & $-0.0502^{\star \star \star}$ & -0.0248 & -0.0109 \\
\hline & $(0.0160)$ & $(0.0210)$ & $(0.0208)$ & $(0.0191)$ \\
\hline \multirow[t]{2}{*}{ Slope classification } & -0.0061 & -0.025 & 0.0457 & -0.0124 \\
\hline & $(0.0339)$ & $(0.0397)$ & $(0.0394)$ & $(0.0365)$ \\
\hline Sample size & 195 & 195 & 195 & 195 \\
\hline Log likelihood & -122 & -135 & -134 & -113 \\
\hline McKelvey and Zavoina's $R^{2}$ & 0.31 & 0.26 & 0.36 & 0.17 \\
\hline Percent correctly predicted & 80 & 62 & 72 & 77 \\
\hline
\end{tabular}

Notes: Standard errors are in parentheses. Asterisks $\left(* \star \star \star \star *\right.$, and $\left.{ }^{\star}\right)$ indicate significance at the $1 \%, 5 \%$, and $10 \%$ levels, respectively.

hypothesis that the probit ML coefficients were not different from zero was rejected at the $1 \%$ level of significance. Variables significant at the $10 \%$ level or lower are discussed.

Older producers were less likely to adopt rotational grazing, water tanks, and stream crossings (Table 2). Producers with a college education were 0.10 more likely to adopt pasture improvement practices and 0.11 more likely to adopt stream crossings. Respondents planning to pass their farm on to family members were $0.22,0.24$, and 0.29 more likely to adopt rotational grazing, water tanks, and pasture rehabilitation, respectively. 
Larger farms were less likely to adopt pasture improvement or rotational grazing than smaller farms, but more likely to adopt stream crossings (Table 3). Operators managing relatively more of their land as pasture were less likely to adopt rotational grazing. Respondents using higher stocking rates were also less likely to adopt rotational grazing; for a 1-unit change in the number of beef cattle grazed on pasture, the likelihood of adopting rotational grazing decreased by 0.07 . This is a surprising result. On average, respondents managing relatively more cattle per acre ostensibly perceive the opportunity costs and extra level of management needed to move cattle from one paddock to another to be too high. Land tenure had a positive effect on the adoption of rotational grazing, but a negative effect on the adoption of water tanks and stream crossings. The latter results are also unexpected. The simple Pearson's correlation $(r)$ between land tenure and acres owned also suggests a significant inverse relationship between these two variables $(r=-0.16$, $P<0.05)$. Thus, tenure rates are relatively higher for smaller operations in the study region. A possible explanation could be that owners of relatively smaller operations are less willing to invest in structures that require additional management. Assessed property value had a negative effect on the adoption of pasture improvement and rotational grazing. For a dollar increase in the assessed property value of a parcel, the probability of adopting pasture improvement decreased by 0.03 and the probability of adopting rotational grazing decreased by 0.05 . One explanation for this finding might be that owners of more highly valued property perceive the opportunity cost of beef cattle production to be higher and are, thus, less committed to producing cattle in the future.

There is evidence of interrelationships between the BMPs used by operators and willingness to adopt the choice experiment's BMPs (Table 3). Producers who had either previously improved pasture or who already practiced rotational grazing were 0.15 more likely to be willing to adopt or increase the extent to which they had adopted rotational grazing. Similarly, producers who had previously improved pasture were 0.17 more likely to be willing to adopt water tanks. Producers who already used water tanks were 0.12 more likely to be willing to install additional water tanks through the hypothetical cost share program. The results were mixed for willingness to adopt stream crossings. Producers who used tanks to water cattle were 0.14 less likely to adopt a stream crossing system at the offered cost share rate, while producers who had already installed or managed stream crossing systems were 0.10 more likely to be willing to adopt additional stream crossings.

\subsection{Response to incentives and pasture BMP adoption}

SUR and SUR with sample selection estimates of the SNQ profit function violated the convexity requirement. Both models were reestimated, imposing convexity. The null hypothesis that the coefficients on the PDF variables in equation (4) were jointly equal to zero was rejected at the $1 \%$ level of significance (LR test $=33$, degrees of freedom $=4$ ). The Breusch-Pagan test for diagonality of the system's error covariance matrix was rejected at the $1 \%$ level (test statistic $=121$, degrees of freedom $=6$; Table 4). The preferred model is therefore the SNQ indirect profit function estimated as a two-step SUR with convexity imposed.

Complementary effects are evident for water tanks and rotational grazing according to their cross-incentive supply elasticities (Table 5). When the cost share incentives of rotational grazing and water tanks are simultaneously increased by $1 \%$, their combined effect results in a $1.3 \%$ change in acres enrolled into the hypothetical rotational grazing program. Larger percent increases in the rotational grazing and water tank costs shares induced an even larger response. If the cost share rates for rotational grazing and water tanks were increased by $14.49 \%$ and $12.56 \%$ to their market values (100\% cost share), then the corresponding change in acres in rotational grazing are $17.58 \%$. For water tanks and rotational grazing, the incentive for their adoption appears to "crowd in" private investment in the form of additional acres in rotational grazing or additional water tanks (Fleming, 2017).

A $1 \%$ increase in the incentive offered to adopt pasture improving practices corresponds with a $-0.11 \%$ decrease in areas respondents are willing to manage with a rotational grazing system, 
Table 4. Seemingly unrelated regression: symmetric indirect normalized quadratic profit function

\begin{tabular}{|c|c|c|c|}
\hline Parameter $1 /$ & Estimate & Standard Error & Z-Score \\
\hline$b_{P}$ & 60.80 & 11.95 & 5.09 \\
\hline$b_{R}$ & 0.78 & 37.81 & 0.02 \\
\hline$b_{w}$ & 0.10 & 1.88 & 0.05 \\
\hline$b_{S}$ & 593.46 & 785.54 & 0.76 \\
\hline$b_{P P}$ & 0.20 & 2.51 & 0.08 \\
\hline$b_{P R}$ & -7.76 & 27.09 & -0.29 \\
\hline$b_{P W}$ & -0.39 & 1.42 & -0.28 \\
\hline$b_{P S}$ & 7.95 & 27.51 & 0.29 \\
\hline$b_{R R}$ & 299.57 & 178.57 & 1.68 \\
\hline$b_{R W}$ & 15.24 & 9.31 & 1.64 \\
\hline$b_{R S}$ & -307.05 & 184.33 & -1.67 \\
\hline$b_{w w}$ & 0.78 & 0.65 & 1.19 \\
\hline$b_{w s}$ & -15.62 & 9.35 & -1.67 \\
\hline$b_{S S}$ & 314.72 & 193.15 & 1.63 \\
\hline$\rho_{P}$ & 0.42 & 0.48 & 0.86 \\
\hline$\rho_{s}$ & 0.05 & 0.68 & 0.07 \\
\hline$\rho_{W}$ & -0.24 & 0.56 & -0.44 \\
\hline$\rho_{R}$ & 0.42 & 1.20 & 0.35 \\
\hline$\sigma_{P}$ & 66.77 & 9.01 & 7.41 \\
\hline$\sigma_{R}$ & 66.47 & 8.23 & 8.08 \\
\hline$\sigma_{W}$ & 1.66 & 0.13 & 13.12 \\
\hline$\sigma_{s}$ & 621.91 & 103.91 & 5.99 \\
\hline Sample size & & 195 & \\
\hline$R^{2}:$ prescribed grazing & & 0.34 & \\
\hline$R^{2}$ : rotational grazing & & 0.28 & \\
\hline$R^{2}:$ water tanks & & 0.48 & \\
\hline$R^{2}:$ stream crossing & & 0.13 & \\
\hline Unrestricted log likelihood & & $-4,035$ & \\
\hline Restricted log likelihood & & $-4,057$ & \\
\hline Breusch-Pagan test 2/ & & 121 & \\
\hline
\end{tabular}

Notes: 1 , Parameter labels are described in equations (1) and (2). 2/, The null hypothesis is that the off-diagonal elements of the error covariance matrix are zero. The statistic is a chi-squared random variable, with a critical value of 12.59 at the $5 \%$ level of significance. $P$, prescribed grazing; $R$, rotational grazing; $S$, stream crossing; $W$, water tank.

thereby "crowding out" private investment (Fleming, 2017). The incentive for water tanks crowds out willingness to improve pasture as a $1 \%$ increase in the incentive offered to adopt a water tank is associated with a $0.54 \%$ decrease in the number of pasture acres respondents are willing to rehabilitate (Table 5). 
Table 5. Supply elasticities for pasture best pasture management practices (standard errors in parentheses)

\begin{tabular}{ccccc}
\hline & Pasture Improvement & Rotational Grazing & Water Tanks & Stream Crossing \\
\hline Pasture improvement & 0.17 & -0.11 & -0.08 & 0.01 \\
\hline Rotational grazing & $(0.09)$ & $(0.07)$ & $(0.04)$ & $(0.01)$ \\
\hline & -1.11 & 0.73 & 0.57 & -0.09 \\
\hline Water tanks & $(0.68)$ & $(0.53)$ & $(0.44)$ & $(0.07)$ \\
\hline Stream Crossing & -0.54 & 0.36 & 0.32 & -0.05 \\
\hline & $(0.55)$ & $(0.43)$ & $(0.37)$ & $(0.05)$ \\
\hline & 0.25 & -0.17 & -0.12 & 0.02 \\
\hline
\end{tabular}

(a)

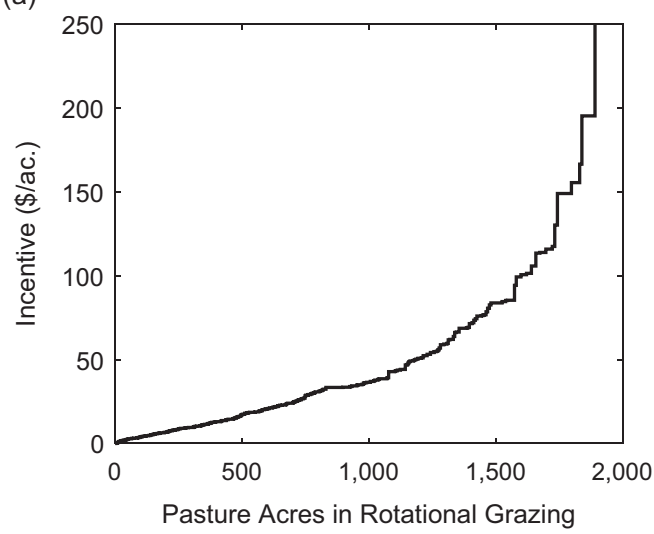

(c)

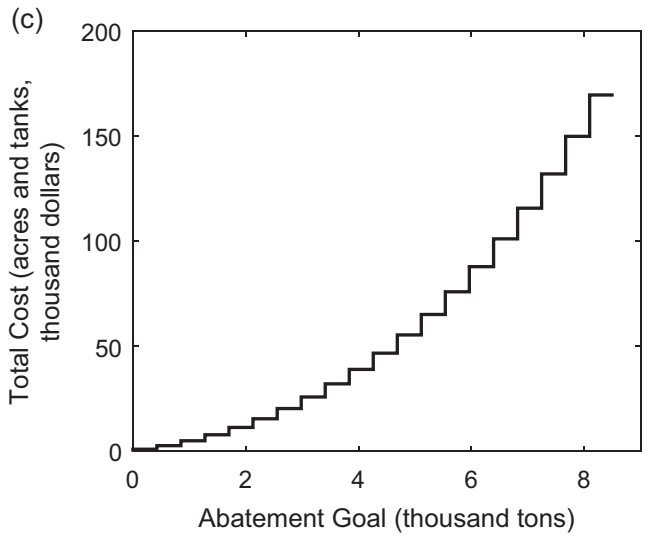

(b)

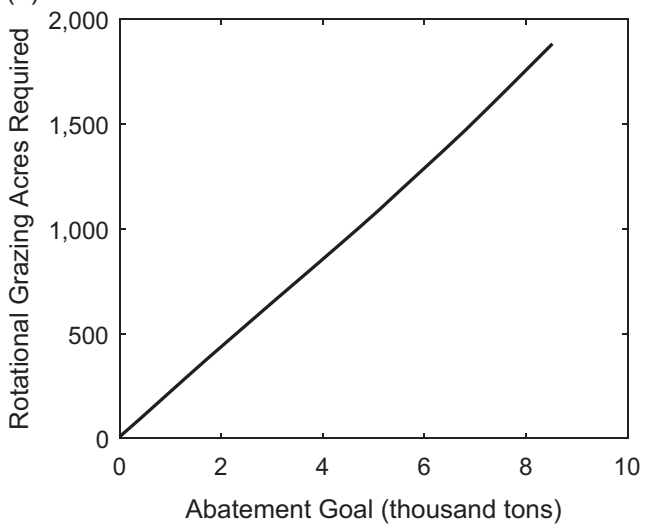

(d)

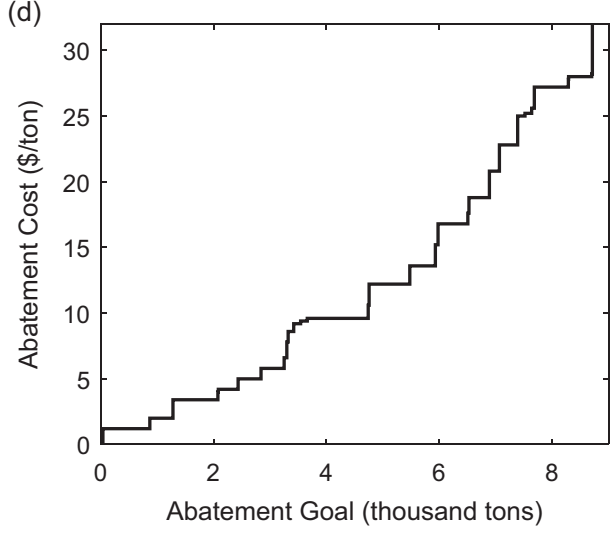

Figure 2. Pasture supply and sediment abatement curves.

\subsection{Application results}

The maximum number of acres that could be enrolled into the hypothetical rotational grazing program, subject to the optimization model's constraints and parameters, is 1,891 (Figure 2a), or $39 \%$ of the total acres included in the simulation sample. The acreage supply curve becomes perfectly inelastic at the cost share rate of $\$ 198 /$ acre, which corresponds with a sediment 
abatement target of 8,520 tons/year (Figure 2b). The maximum feasible sediment abatement target of 8,520 tons/year corresponds with a $37 \%$ reduction in sedimentation for the 52 HRUs included in the simulation, and a $31 \%$ overall reduction in sediment loading for all 207 pasture HRUs in the watershed. At this level of sediment abatement, total incentive payments for enrolled acres and water tanks are estimated to be $\$ 170,000$ per year (Figure 2c), or roughly $\$ 20 /$ ton of decreased sediment yield (Figure 2d).

\section{Conclusions}

This study uses the results of a hypothetical choice experiment measuring cattle producer willingness to adopt four pasture-based best management practices (rotational grazing, pasture improvement, water tanks, and stream crossings) to estimate a theoretically consistent system of supply (or extent of adoption) equations. The usual constraints of homogeneity, symmetry, and convexity were imposed, and a two-step nonlinear procedure was used to estimate the indirect profit function. The supply equation for any one practice quantifies the relationship between acres or units of the practice likely to be adopted by livestock producers and the incentive level offered for the adoption of the practice (the own-incentive), holding the incentive levels for the other practices (the cross-incentives) constant.

The supply equation for rotational grazing was linked to a SWAT to simulate the effects of the adoption of rotational grazing on sediment yields to generate an aggregate sediment abatement curve for a watershed in East Tennessee. The sediment abatement curve summarizes the relationship between the land class-specific incentive levels for rotational grazing and watershed-level reductions in sediment yield. Thus, the abatement curve differentiates among the land classes based on sediment yield rates and implicitly assumes an incentive program that can target land classes because of this difference.

Application of the methods used here would enable agencies to consider the effects of both own- and cross-incentive elasticities on practice adoption and sedimentation abatement when defining and setting incentives for a suite of best management practices. Previous studies established the existence of cross-incentive effects but did not apply methods to account for these effects when setting incentive rates. Thus, this study extends this literature by proposing an empirical strategy for generating theoretically consistent own- and cross-incentive effects for a suite of pasture management best management practices and then linking these effects with a biophysical simulation model to generate sediment reduction cost curves as well as the corresponding acreage supply/cost rate schedule. In this way, the article proposes an approach for resolving some of the complexities involved in setting incentive rates that will both entice producers to adopt BMPs while cost-effectively achieving desirable environmental outcomes.

The results should be put into perspective. The findings of the choice experiment are subject to all of the usual qualifications regarding hypothetical markets. In addition, there were limitations to the choice experiment performed for this analysis. Landowners who used pasture to raise beef cattle with access to streams were the larger population of interest in this study. The number of landowners meeting these criteria was unknown before the survey. This means the sample used may underrepresent the population of interest. In terms of the estimation of the best management practice supply equations, the two-step procedure used here generates consistent estimates, but these estimates are inefficient compared with full-information ML estimators. However, the advantage of the two-step estimator rests in the relative ease at which nonlinearities can be introduced into supply equations to impose a function consistent with profit maximizing behavior. An empirical challenge remains to specify fully the system proposed here as a "full-information" system of censored equations with curvature imposed by the procedures used here. ${ }^{4}$

\footnotetext{
${ }^{4}$ Recent advances in modeling demand systems by, for example, Plastina and Lence (2018) hold some promise. Adapting their simulation approach to censoring mechanisms is a challenge for future applications.
} 
Further, one might expect willingness to adopt to vary with the characteristics of the land classes. For example, owners of steeper land classes might be more willing to adopt erosion-reducing practices because of higher erosion rates and, possibly, lower opportunity costs. Thus, additional research could focus on differentiating between land classes both in terms of sediment yields and between producer willingness to adopt best pasture practices.

Supplementary material. To view supplementary material for this article, please visit https://doi.org/10.1017/aae.2019.42.

Acknowledgments. The authors thank the editor and three anonymous reviewers whose comments and suggestions greatly improved earlier versions of the manuscript. Any remaining errors are those of the authors. The views herein are solely those of the authors.

Financial support. This research was funded by the U.S. Department of Agriculture under Award No. 2009-51130-06047, the Willard Sparks Endowment, Chair of Agricultural Sciences and Natural Resources.

Conflict of interest. None.

\section{References}

Baumgart-Getz, A., L. Prokopy, and K. Flores. "Why Farmers Adopt Best Management Practices in the United States: A Meta-analysis of the Adoption Literature." Journal of Environmental Management 96, 1(2012):17-25.

Breusch, T.S., and A.R. Pagan. "The Lagrange Multiplier Test and Its Applications to Model Specification in Econometrics." Review of Economic Studies 47, 1(1980):239-53.

Cameron, A.C., and P.K. Trivedi. Microeconometrics. Cambridge: Cambridge University Press, 2005.

Chambers, R.G. Applied Production Analysis: A Dual Approach. Cambridge: Cambridge University Press, 1988.

Claytor, H.S., C.D. Clark, D.M. Lambert, and K.L. Jensen. "Cattle Producer Willingness to Afforest Pastureland and Sequester Carbon." Forest Policy and Economics 92(July 2018):43-54.

Daberkow, S.G., and W.D. McBride. "Farm and Operator Characteristics Affecting the Awareness and Adoption of Precision Agriculture Technologies in the U.S." Precision Agriculture 4, 2(2003):163-77.

Diewert, W.E., and T.J. Wales. "Flexible Function Forms and Global Curvature Conditions." Econometrica 55, 1(1987): 43-68.

Diewert, W.E., and T.J. Wales. “Quadratic Spline Models for Producer's Supply and Demand Functions.” International Economic Review 33, 3(1992):705-22.

Fernandez-Cornejo, J., S. Daberkow, and W.D. McBride. "Decomposing the Size Effect on the Adoption of Innovations: Agrobiotechnology and Precision Agriculture.” AgBioForum 4, 2(2001):124-36.

Fleming, P. "Agricultural Cost Sharing and Water Quality in the Chesapeake Bay: Estimating Indirect Effects of Environmental Payments.” American Journal of Agricultural Economics 99, 5(2017):1208-27.

Gassman, P.W., M.R. Reyes, C.H. Green, and J.G. Arnold. "The Soil and Water Assessment Tool: Historical Development, Applications, and Future Research Directions." Transactions of the ASABE 50, 4(2007):1211-50.

Gesch, D.B., M.J. Oimoen, S.K. Greenlee, C.A. Nelson, M.J. Stuek, and D.J. Tyler. "The National Elevation Data Set." Photogrammetric Engineering and Remote Sensing 68, 1(2002):5-11.

Gillespie, J., S. Kim, and K. Paudel. 2007. "Why Don't Producers Adopt Best Management Practices? An Analysis of the Beef Cattle Industry.” Agricultural Economics 36, 1(2007):89-102.

Govindasamy, R., and M.J. Cochran. "The Conservation Compliance Program and Best Management Practices: An Integrated Approach for Economic Analysis." Review of Agricultural Economics 17, 3(1995):369-81.

Govindasamy, R., and W. Huffman. "Efficiency of U.S. Conservation-Compliance Program." Agricultural Economics 8, 2(1993):173-85.

Henningsen, A. Introduction to Econometric Production Analysis with R. Copenhagen: Department of Food and Resource Economics, University of Copenhagen, 2018.

Henningsen, A., and C. Henning. "Imposing Regional Monotonicity on Translog Stochastic Production Frontiers with a Simple Three-Step Procedure." Journal of Productivity Analysis 32, 3(2009):217-29.

Jensen, K.L., D.M. Lambert, C.D. Clark, B.C. English, T.E. Yu, J.A. Larson, C. Holt, and C.M. Hellwinckel. "Cattle Producers' Willingness to Adopt or Expand Prescribed Grazing in the United States." Journal of Agricultural and Applied Economics 47, 2(2015):213-42.

Johnson, D.M., and R. Mueller. “The 2009 Cropland Data Layer.” Photogrammetric Engineering and Remote Sensing 76, 11(2010):1201-5.

Kasteridis, P., S.T. Yen, and C. Feng. "Bayesian Estimation of a Censored Linear Almost Ideal Demand System: Food Demand in Pakistan." American Journal of Agricultural Economics 93, 5(2011):1374-90. 
Kim, S.A., J.M. Gillespie, and K.P. Paudel. "The Effect of Socioeconomic Factors on the Adoption of Best Management Practices in Beef Cattle Production." Journal of Soil and Water Conservation 60, 3(2005):111-20.

Kim, S.A., J.M. Gillespie, and K.P. Paudel. "Rotational Grazing Adoption in Cattle Production under a Cost-Share Agreement: Does Uncertainty Have a Role in Conservation Technology Adoption?” Australian Journal of Agricultural and Resource Economics 52, 3(2008):235-52.

Knowler, D., and B. Bradshaw. "Farmers' Adoption of Conservation Agriculture: A Review and Synthesis of Recent Research." Food Policy 32, 1(2007):25-48.

Koebel, B. "Tests of Representative Firm Models: Results for German Manufacturing Industries." Journal of Productivity Analysis 10, 3(1998):251-70.

Kohli, U.R. "A Symmetric Normalized Quadratic GNP Function and the US Demand for Imports and Supply of Exports." International Economic Review 34, 1(1993):243-55.

Lambert, D.M., C.D. Clark, N. Busko, F.R. Walker, A. Layton, and S. Hawkins. "A Study of Cattle Producer Preferences for Best Management Practices in an East Tennessee Watershed." Journal of Soil and Water Conservation 69, 1(2014): $41-53$.

Lau, L.J. “Testing and Imposing Monotonicty, Convexity, and Quasi-convexity Constraints.” Production Economics: A Dual Approach to Theory and Applications Volume I: The Theory of Production, M. Fuss and D.L. McFadden, eds. Amsterdam: North-Holland, 1978, pp. 409-53.

Leeper, R.D., J. Rennie, and M.A. Palecki. "Observational Perspectives from US Climate Reference Network (USCRN) and Cooperative Observer Program (COOP) Network: Temperature and Precipitation Comparison.” Journal of Atmospheric and Oceanic Technology 32, 4(2015):703-21.

Liu, T., R.J.F. Bruins, and M.T. Heberling. "Factors Influencing Farmers' Adoption of Best Management Practices: A Review and Synthesis." Sustainability 10, 2(2018):432.

Maddala, G.S. Limited-Dependent and Qualitative Variables in Econometrics. Cambridge: Cambridge University Press, 1983.

McKelvey, R.D., and W. Zavoina. "A Statistical Model for the Analysis of Ordinal Level Dependent Variables." Journal of Mathematical Sociology 4, 1(1975):103-12.

Medwid, L. "Incentives for Best Management Practice Adoption among Beef Cattle Producers and Effects on Upland Sediment Loss: A Case Study in Southeastern Tennessee.” Master's thesis, University of Tennessee, Knoxville, 2016.

Pannell, D., R. Llewellyn, and M. Corbeels. "The Farm-Level Economics of Conservation Agriculture for Resource-Poor Farmers." Agriculture, Ecosystems and Environment 187, 1(2014):52-64.

Paudel, K.P., and C.S. McIntosh. "Numeraire Choice in Agricultural Supply Analysis." Applied Economics 37, 11(2007):1209-14.

Perali, F., and J.P. Chavas. "Estimation of Censored Demand Equations from Large Cross-Section Data." American Journal of Agricultural Economics 82, 4(2000):1022-37.

Plastina, A., and S. Lence. "A Parametric Estimation of Total Factor Productivity and Its Components in U.S. Agriculture." American Journal of Agricultural Economics 100, 4(2018):1091-119.

Prokopy, L., K. Floress, D. Klotthor-Weinkauf, and A. Baumgart-Getz. "Determinants of Agricultural Best Management Practice Adoption: Evidence from the Literature." Journal of Soil and Water Conservation 63, 5(2008):300-11.

Roberts, R.K., B.C. English, J.A. Larson, R.L. Cochran, W.R. Goodman, S.L. Larkin, M.C. Marra, S.W. Martin, W.D. Shurley, and J.M. Reeves. "Adoption of Site-Specific Information and Variable Rate Technologies in Cotton Precision Farming." Journal of Agricultural and Resource Economics 36, 1(2004):143-58.

Schimmelpfennig, D., and R. Ebel, On the Doorstep of the Information Age: Recent Adoption of Precision Agriculture. Washington, DC: U.S. Department of Agriculture, Economic Research Service, Economic Information Bulletin No. 80, 2011.

Shonkwiler, J.S., and S.T. Yen. “Two-Step Estimation of a Censored System of Equations.” American Journal of Agricultural Economics 81, 4(1999):972-82.

Smale, M., and P.W. Heisey. "Simultaneous Estimation of Seed-Fertilizer Adoption Decisions - An Application to Hybrid Maize in Malawi." Technological Forecasting and Social Change 43, 3-4(1993):353-68.

Smith, C.M., J.R. Williams, A. Nejadhashemi, S.A. Woznicki, and J.C. Leatherman. "Cost-Effective Targeting for Reducing Soil Erosion in a Large Agricultural Watershed." Journal of Agricultural and Applied Economics 46, 4(2014):509-26.

StataCorp. STATA 15 Software. College Station, TX: StataCorp, 2015.

Su, S.-J.B., and S.T. Yen. "A Censored System of Cigarette and Alcohol Consumption." Applied Economics 32, 6(2000): 729-38.

Undersander, D., B. Albert, D. Cosgrove, D. Johnson, and P. Peterson. Pastures for Profit: A Guide to Rotational Grazing. Madison: Cooperative Extension, University of Wisconsin-Extension, 2002.

U.S. Department of Agriculture, Natural Resource Conservation Service. (2018) “Geospatial Data Gateway.” Internet site: https://datagateway.nrcs.usda.gov/ (Accessed May 5, 2018).

Wang, X., and A.M. Melesse. "Effects of STATSGO and SSURGO as Inputs on SWAT Model's Snowmelt Simulation." Journal of the American Water Resources Association 42, 5(2006):1217-36. 
Watcharaanantapong, P., R.K. Roberts, D.M. Lambert, J.A. Larson, M. Velandia, B.C. English, R.M. Rejesus, and C. Wang. "Timing of Precision Agriculture Technology Adoption in US Cotton Production." Journal of Precision Agriculture 15, 4(2014):427-46.

White, M.J., D.E. Storm, P. Busteed, S. Stoodley, and S.J. Phillips. "Evaluating Conservation Program Success with Landsat and SWAT.” Environmental Management 45, 5(2010):1164-74.

Yen, S.T. "A Multivariate Sample-Selection Model: Estimating Cigarette and Alcohol Demands with Zero Observations." American Journal of Agricultural Economics 87, 2(2005):453-66.

Yen, S.T., K. Kan, and S.-J. Su. "Household Demand for Fats and Oils: Two-Step Estimation of a Censored Demand System." Applied Economics 34, 14(2002):1799-806.

Yen, S.T., and B-H Lin. "A Sample Selection Approach to Censored Demand Systems." American Journal of Agricultural Economics 88, 3(2006):742-49.

Zellner, A. "An Efficient Method of Estimating Seemingly Unrelated Regressions and Tests for Aggregation Bias." Journal of the American Statistical Association 57, 298(1962):348-68.

Cite this article: Lambert DM, Clark CD, Medwid LJ, Hawkins SA, and McClellan HA (2020). Best pasture management practice adoption and sediment abatement. Journal of Agricultural and Applied Economics 52, 204-221. https://oi.org/ 10.1017/aae.2019.42 